\title{
Ultrastructure of Candida albicans Pleomorphic Forms: Phase-Contrast Microscopy, Scanning and Transmission Electron Microscopy
}

\author{
MONIKA STANISZEWSKA ${ }^{1 *}$, MAŁGORZATA BONDARYK ${ }^{1}$, KATARZYNA SIENNICKA $^{2}$ \\ and WIESŁAW KURZĄTKOWSKI ${ }^{1}$
}

\author{
${ }^{1}$ National Institute of Public Health-National Institute of Hygiene, Warsaw, Poland \\ ${ }^{2}$ Warsaw University of Life Sciences, Poland
}

Received 13 November 2011, revised 30 January 2012, accepted 9 February 2012

\author{
Abstract
}

A modified method of glutaraldeyde-osmium tetroxide fixation was adjusted to characterize the ultrastructure of Candida albicans pleomorphic forms, using phase-contrast microscopy, scanning electron microscopy and transmission electron microscopy. The discovered morphological criteria defining the individual morphotypes are discussed in terms of mycological and histopathological diagnostics of candidiasis. The relations are discussed between fungal pleomorphism, virulence and susceptibility of different morphotypes to fungicides.

Ke y words: Candida albicans, diagnostics, morphotypes, ultrastructure

\section{Introduction}

Candida albicans exists in different morphotypes. From the evolutionary point of view the round blastoconidia are adjusted to a fluid medium where the round single cells can be easily disseminated through micro streaming. On the contrary, the mycelium building true hyphae and pseudohyphae are adjusted to grow into solid and half solid substrates. All these morphotypes are adaptations to maximal exploitation of nutrition elements from fluid and solid substrates (Müller and Melchinger, 2006). On the other hand, these morphotypes are also related to virulence and fungicidal resistance of C. albicans clinical isolates (Salfelder et al., 1990; Kurzątkowski et al., 2010; Staniszewska et al., 2010).

Candida albicans is an opportunistic pathogen (Okawa et al., 2007; Raška et al., 2007; Netea et al., 2008; Nguyen et al., 2011). This fungus exist in few morphological phenotypes, which are genetically determined and therefore the exactly defined criteria of these morphotypes will provide important attributes in the mycological and histopathological diagnostics of candidiasis. At present, ultrastructural attributes of these morphotypes should be completed. So far released publications suggest that the extremely thick and compact cell wall of C. albicans prevents the cytoplasm fixation hampering the ultrastructure presentation (Müller and
Melchinger, 2006) and therefore for this yeast a novel and better adjusted method should be employed.

This experimental study was designed to provide some exact ultrastructural criteria defining C. albicans morphotypes using a novel modified method of glutaraldehyde-osmium tetroxide fixation.

\section{Experimental}

Material and Methods

Strain. The Candida albicans 82 clinical strain examined in this experimental program was isolated from a blood sample taken from a three-years-old child treated for an ependymoma anaplasticum. The strain was identified using: CHROMagar Candida (BioMèrieux) (Staniszewska et al., 2011b), API23C AUX (BioMèrieux, Lyon, Marcy-l' Etoile, France) (Staniszewska et al., 2011a) and genetic procedures (in preparation). The investigated strain created pleomorphic cells viable under phasecontrast microscopy (Docuval, Carl Zeiss, Jena) (Staniszewska et al., 2011a), scanning electron microscopy (SEM Quanta-200, FEI, Czech Republic) (Kurzątkowski et al., 2010; Staniszewska et al., 2011b) and transmission electron microscopy (TEM Zeiss EM LIBRA 120, Carl Zeiss, Germany) (Kurzątkowski et al., 2010).

${ }^{\star}$ Corresponding author: M. Staniszewska, Division of Epidemiology and Microbiology, National Institute of Public Health-National Institute of Hygiene, Chocimska 24, Warsaw 00-791, Poland; phone: + 4822542 1228; fax: + 4822849 7484; e-mail: mstaniszewska@pzh.gov.pl 
Induction of blastoconidial forms in YEPD medium. A single colony of blastoconidia grown on Sabouraud medium was inoculated in $5 \mathrm{ml}$ of YEPD (Ness et al., 2010) liquid medium (pH 5.7) and the culture was incubated at $30^{\circ} \mathrm{C}$ for $18 \mathrm{~h}$ (stationary phase) to a final concentration of: $1.5 \times 10^{7} \mathrm{CFU} \mathrm{ml}{ }^{-1}$, estimated using the Thomas Chamber under a phase-contrast microscopy.

Induction of pseudohyphae in 5\% human serum. The human serum was obtained from healthy volunteers (Institute of Hematology and Transfusion Medicine in Warsaw) as a kind gift from Ph.D. G. SmoleńskaSym. The serum was filtered using Millex filter with $0.45 \mu \mathrm{m}$ millipore membrane (Millipore, Carrigtwohill, Ireland). The filtered serum was diluted with sterile distilled water to a final concentration of 5\%. Fifty $\mu \mathrm{l}$ of blastoconidial cells (stationary phase) of the strain C. albicans 82 grown on YEPD medium were added to Eppendorf vials containing diluted human serum (500 $\mu \mathrm{l}, \mathrm{pH}$ 8.0-8.2). To examine the transfer of blastoconidia into pseudohyphae incubation was conducted at $37^{\circ} \mathrm{C}$ for $48 \mathrm{~h}$.

Induction of germ tubes and true hyphae in undiluted human serum. Fifty $\mu$ l of blastoconidial cells (stationary-phase) of the analysed strain C.albicans 82 grown on YEPD medium were added to Eppendorf vials containing filtered undiluted human serum (500 $\mu \mathrm{l}, \mathrm{pH}$ 7.1-7.4). To examine the transfer of blastoconidia into filaments, incubation was conducted at $37^{\circ} \mathrm{C}$ for the following period: $1-18 \mathrm{~h}$.

Phase-contrast microscopy. Pleomorphic cells were washed once with sterile water and then suspended in $500 \mu \mathrm{l}$ of water. Ten $\mu \mathrm{l}$ of the suspension were pipetted onto slide and a coverslip was placed over the sample, and then examined under the phase-contrast microscopy (Staniszewska et al., 2011a).

Transmission and scanning electron microscopy. Blastoconidia, germ tubes, pseudohyphae and true hyphae ( $5 \mathrm{ml}$ of cultures) were harvested by centrifugation at $1600 \mathrm{~g}$ for $5 \mathrm{~min}$ (MPW-360; Mechanika Precyzyjna, Warsaw, Poland). The pellets were used to prepare samples for transmission electron microscopy and scanning electron microscopy. Preparation for transmission electron microscopy was performed as described previously (Kuryłowicz et al., 1980) with the exception of the fixation methods which were conducted in $3.5 \%$ or $4.5 \%$ glutaraldehyde (Sigma-Aldrich, Milwaukee, WI, USA) for $6 \mathrm{~h}$ at $2^{\circ} \mathrm{C}$, and then continued with $1.2 \%$ osmium tetroxide (Sigma-Aldrich, Milwaukee, WI, USA) solution for $2 \mathrm{~h}$. All samples were dehydrated in increasing concentrations of ethyl alcohol and embedded in Epon 812 (Serva-Electrophoresis, Heidelberg, Germany) at room temperature. The blocs were polymerized at $37^{\circ} \mathrm{C}$ for $24 \mathrm{~h}$ and at $65^{\circ} \mathrm{C}$ for $48 \mathrm{~h}$, and cut on LKB III Ultra Microtome (Diversified
Equipment, Inc., Lorton, VA, USA). The sections were stained with uranyl acetate solution and then treated with Reynold's reagent (Serva-Electrophoresis, Heidelberg, Germany). The ultra thin sections were examined under transmission electron microscopy JOEL, JEM1220 (Tokyo, Japan).

Scanning electron microscopy (FEI QUANTA 200, Hillsboro, OR, USA) was conducted as described previously (Kurzątkowski et al., 2010). The samples were coated with a gold film (thickness approximately $20 \mathrm{~nm}$ ) under vacuum in an argon atmosphere using a sputter coater (Emscope SC500, Island Scientific Ltd, Isle of Wight, Ventor, UK) prior to SEM analysis.

Morphology index (Mi). The morphotypes were examined under TEM and classified on the basis of $\mathrm{Mi}=l s / d^{2}$ (Merson-Davies and Odds, 1989) The length of the cell (l), maximum diameter of the cell (d) and diameter at the septal junction (s) were determined for 118 randomly selected cells. The Mi values of different pleomorphic forms were analyzed by descriptive statistics (number of cells measured, average, SD, minimum and maximum). Analysis was done using SPSS 12.0/ (//SPSS for Windows, Rel 12.0.1, 2004, Chicago: SPSS INC/).

\section{Results}

Candida albicans cells exhibit typically eukaryotic ultrastructure, i.e.: nucleus, endoplasmic reticulum, Golgi cisternae and mitochondria. Depending on the cultural conditions this fungus is able to develop the following pleomorphic forms: blastoconidia, germ tubes, pseudohyphae and true hyphae. Classification of morphotypes based on Mi value is presented in Table I. The morphological attributes of these forms are different.

Table I

Morphology index (Mi) values for pleomorphic cells of Candida albicans 82 grown from 4 to $48 \mathrm{~h}$ in $5 \%$ human serum at $37^{\circ} \mathrm{C}$. Data estimated by measuring the pleomorphic cells documented by transmission electron micrographs

\begin{tabular}{|c|c|c|c|c|c|}
\hline \multirow{3}{*}{$\begin{array}{l}\text { Pleomorphic } \\
\text { foms }\end{array}$} & \multicolumn{4}{|c|}{ Morphology index (Mi) } & \multirow{3}{*}{$\begin{array}{c}\text { No. } \\
\text { of cells } \\
\text { examined }\end{array}$} \\
\hline & \multicolumn{2}{|c|}{ Range $^{\star}$} & \multirow[b]{2}{*}{ Average } & \multirow{2}{*}{$\begin{array}{l}\text { Standard } \\
\text { deviation }\end{array}$} & \\
\hline & $\begin{array}{l}\text { Mini- } \\
\text { mum }\end{array}$ & $\begin{array}{l}\text { Maxi- } \\
\text { mum }\end{array}$ & & & \\
\hline Yeast & 1.0 & 1.5 & 1.17 & 0.1401 & 71 \\
\hline Germ tube & 1.6 & 2.4 & 1.90 & 0.3327 & 15 \\
\hline Pseudo hyphae & 2.5 & 3.4 & 2.74 & 0.3291 & 15 \\
\hline True hyphae & 4.1 & 17.8 & 7.62 & 3.3039 & 17 \\
\hline Total & 1.0 & 17.8 & 2.39 & 2.5419 & 118 \\
\hline
\end{tabular}

* Classification of tetramorphic forms based on the Mi value: blastoconidia, 1.0-1.5; germ-tube, 1.6-2.4; pseudo-hyphae, 2.5-3.4; true-hyphae $>3.4$ (Merson-Davies and Odds, 1989) 

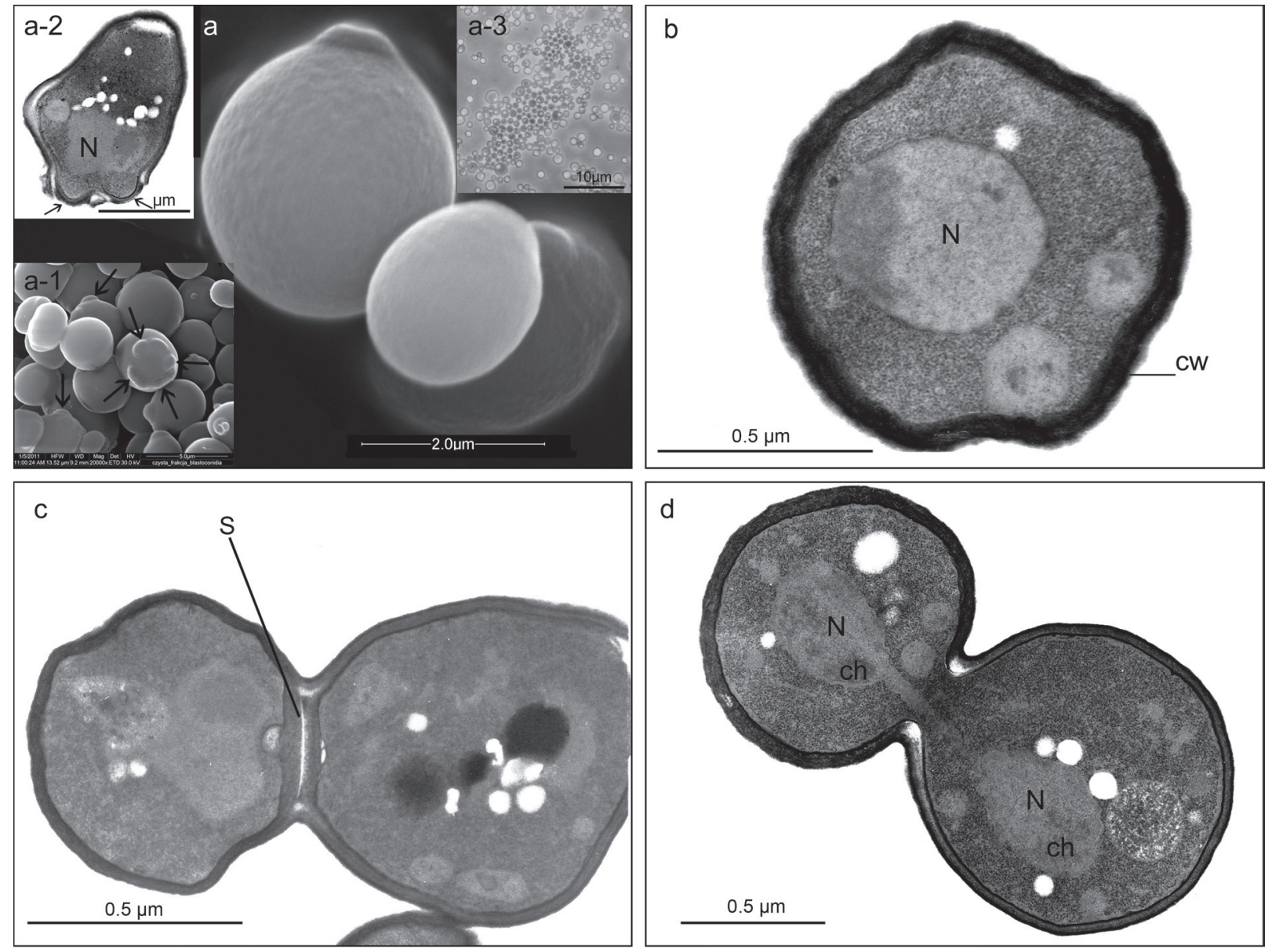

Fig. 1. (a, b, c, d) Blastoconidia of Candida albicans 82 grown in YEPD medium (pH 5.7) at $30^{\circ} \mathrm{C}$ for 18 h: (a, a-1) scanning electron micrographs, (a-2) transmission electron micrograph, (a-3) phase-contrast micrograph, (b, c, d) transmission electron micrographs. (a) Polar budding, (a-1) polar arranged rings of scars (arrows), (a-2) nucleus (N) associated with areas of polar budding (arrows), (a-3) oval budding blastoconidial cells. (b) Massive cell wall $(\mathrm{cw})$ and a longitudinal section through a nucleus (N) at an early state of mitosis. (c) Breakable septum (s). (d) Telophase nucleus (N). The nuclear envelope has broken down in the equatorial region of the nucleus and is reforming around the clusters of chromosomes $(\mathrm{ch})$, thus excluding the spindle which soon breaks down

Blastoconidia appear as oval or spherical cells. The poles of this morphotype are privileged areas of budding or germinating (Figure 1). Massive cell wall of this morphotype is abundantly covered with fibrous material (Figure 1b). The breakable septum is composed of the mother cell wall and a thinner daughter layer (Figure 1c). Using our modified fixation method in the cytoplasm a telophase plasmodial nucleus was documented (Figure 1d). Pseudohyphae can be characterized as chain of elongated budding blastoconidial cells with fragile septa. Pseudohyphae develop directly from blastoconidia or as branches of true hyphae (Figure 2a). The true hyphae grow from adhesive blastoconidia which build after $1 \mathrm{~h}$ of cultivation conglomerates of germ tubes. Polar germination of blastoconidia is a characteristic attribute initiating the growth of true hyphae. After $2 \mathrm{~h}$ of cultivation the length of the radiate extending true hyphae ranges from 5 to $7 \mu \mathrm{m}$ and between $3-6 \mathrm{~h}$ from 10 to $15 \mu \mathrm{m}$. Finally at $18 \mathrm{~h}$ of cultivation the radiate arranged true hyphae build massed conglomerates of about $700 \mu \mathrm{m}$ (average of 25 measurements in diameter) (Figure 2b).

In a distance of about $70 \mu \mathrm{m}$ from the apex of the conglomerate building true hyphae young cells are located. In a further range of the hyphae mature and senescent cells with large vacuoles are visible (Figure 3a). Generally, in comparison with blastoconidial mother cell the surface of hyphal part of germ tube is less covered with fibrous material (Figure $3 b$ ). The massive true hyphal septum fast joined with the cell wall is located in the place of the strongest mechanical stability. The massive septum is a cellular linking binder which is responsible for the extreme durability of the true hyphal structure (Figure 3c). In the examined cultivation conditions until $18 \mathrm{~h}$ of growth budding of true hyphae is very less noticeable. After this period of cultivation in protein exhausted human serum the true hyphae begin the processes of budding or pseudohyphae branching. Privileged areas for these processes are the cytoplasm regions located at the poles of the elongated true hyphal 

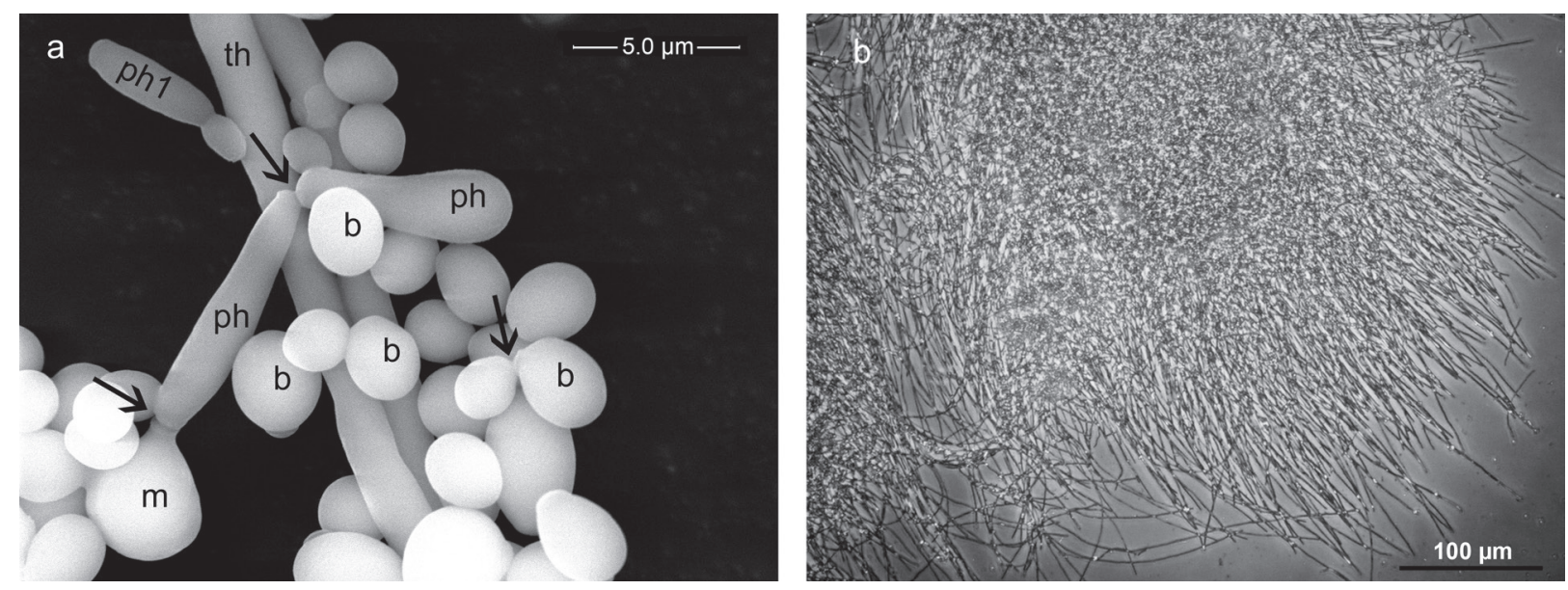

Fig. 2. (a, b) Candida albicans 82. (a) Scanning electron micrograph. (b) Phase-contrast micrograph. (a) Growth in 5\% human serum ( $\mathrm{pH} \mathrm{8.2)}$ at $37^{\circ} \mathrm{C}$ for $48 \mathrm{~h}$. Pleomorphic forms are visible, i.e. (b) oval blastoconidia with fragile septa (arrows), (ph) chains of elongated blastoconidial cells with fragile septa (arrows) forming pseudohyphae $\left(\mathrm{ph}_{1}\right.$ ) from an oval mother cell, (th) uniformly elongated true hyphae. (b) Mycelium building true hyphae grown in undiluted human serum ( $\mathrm{pH} 7.0)$ at $37^{\circ} \mathrm{C}$ for $18 \mathrm{~h}$ form aggregates of blastoconidia (circular dark area)
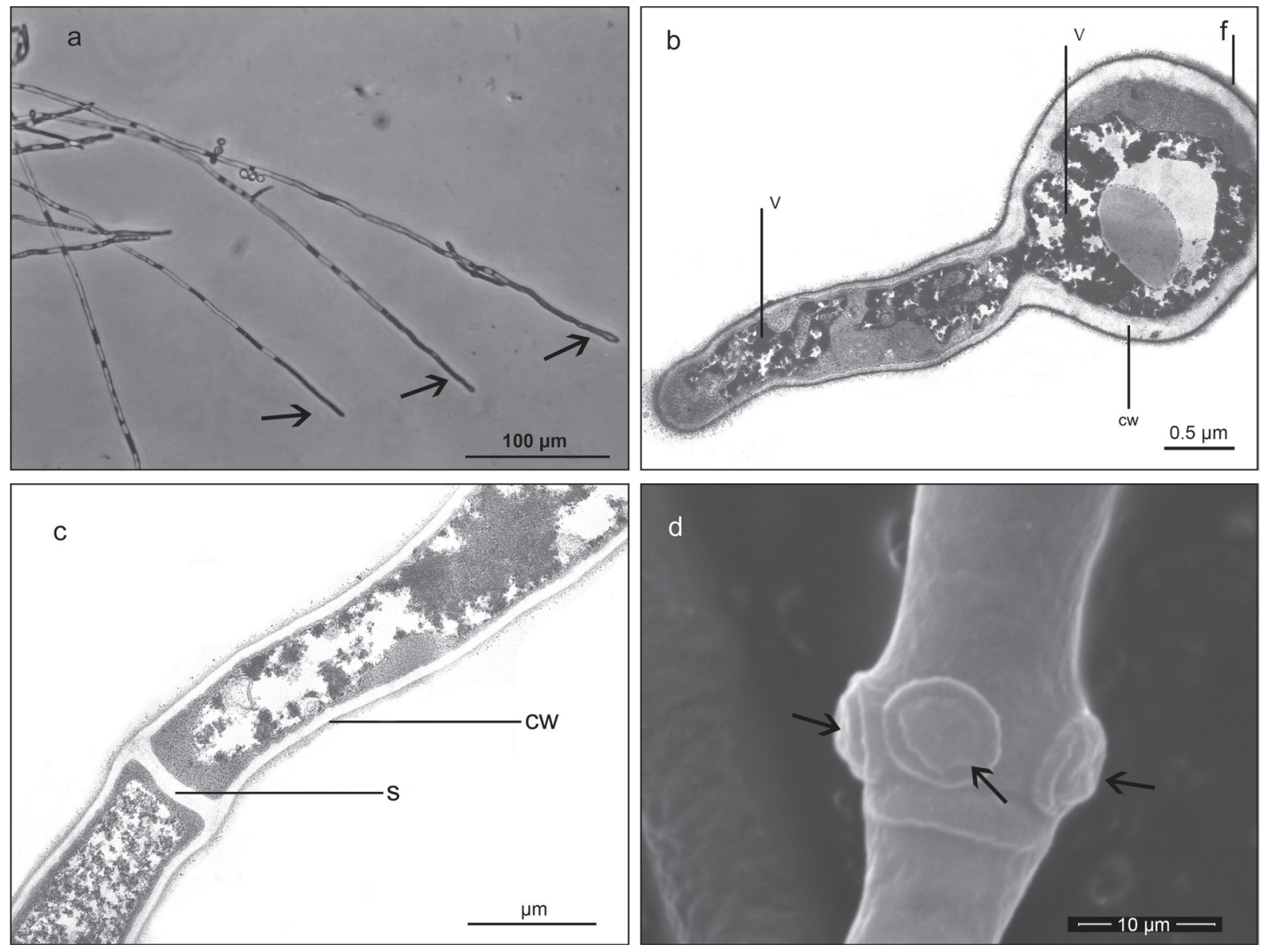

Fig. 3. (a, b, c, d) True hyphae of Candida albicans 82 grown in undiluted human serum ( $\mathrm{pH} 7.0$ ) at $37^{\circ} \mathrm{C}$ for $18 \mathrm{~h}$. (a) Phasecontrast micrographs. (b, c) Transmission electron micrographs. (d) Scanning electron micrographs. (a) Young cells at the hyphal apex (arrows). In a further range from the apex mature and senescent cells with increasing in the length vacuoles from about $10 \mu \mathrm{m}$ to $50 \mu \mathrm{m}$ are visible (light areas). In the direct neighborhood of both sites of the septa dense cytoplasm is located (interrupted dark areas). (b) Blastoconidial mother cell extending into tubular hyphae. Note the dense and strong structure of blastoconidial cell wall (cw). Note the fibrous appearance at the outer surface of the cell wall (f). In contrast, the cell wall of the tubular extending hyphae is less covered with fibrilles. In the cytoplasm vacuoles (v) are visible. (c) Massive true hyphal septum (s) fast joined with the cell wall (cw). (d) Ring of bud scars (arrows) located at one side of the massive true hyphal septum exhibiting privileged places of hyphal budding or branching 


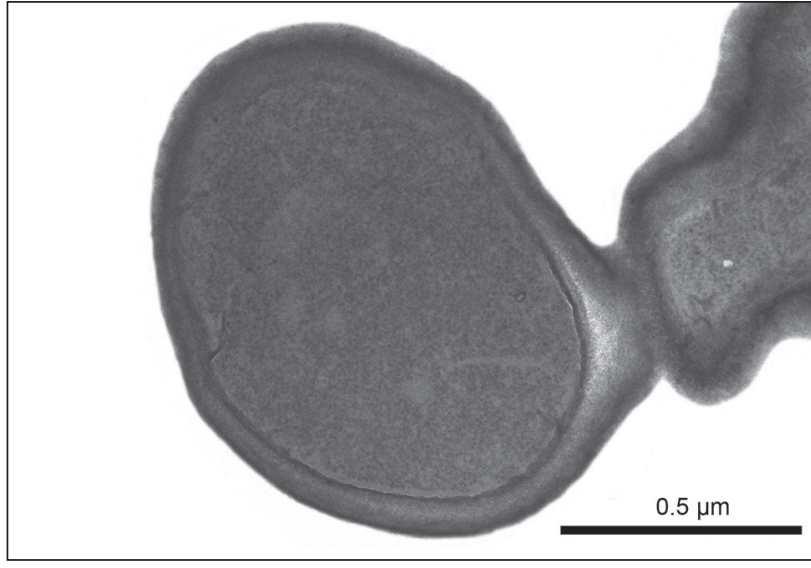

Fig. 4. Candida albicans 82, fixation with 3.5\% glutaraldehyde, $1.2 \%$ osmium tetroxide fixation. The cytoplasm is poorly visible. The novelty of our study is the elaborated fixation method, i.e. $4.5 \%$ instead of $3.5 \%$ glutaraldehyde continued with $1.2 \%$ osmium tetroxide. The improved method allowed the presentation of the ultrastructural details described in Figs. 1a-2, 1b, 1c, 3b, 3c

cells, i.e. at the septa where rings of buds and bud scars (Figure 3d) or pseudohyphal branches were visible. At $3.5 \%$ glutaraldehyde pre-fixation the cytoplasm of the cell is less visible (Figure 4).

\section{Discussion}

The high frequency of occurrence of candidiasis as well as the high mortality of patients with immunosuppression cause a tendency toward better understanding of C. albicans virulence factors and developing sensitive and specific diagnostic methods, and appropriate strategies for candidiasis treatment. Diagnostics of mycoses is based on microscopic, microbiological, serological (detection of antigens and antibodies) as well as molecular methods (Woods and Schnadig, 2003; Przyjałkowski, 2006).

Patients deficient in antibody immune response value and titer give frequently false negative results (Warzocha and Seferyńska, 2006). Moreover, lack of characteristic symptoms in this group of patients impairs recognition of fungal infection based on the clinical picture (Stradomska, 2006). Interpretation of microbiological or molecular results should be correlated with occurring clinical symptoms.

In many cases, obtaining a positives result from a direct clinical material preparation is the only certain way of recognizing mycoses (Warzocha and Seferyńska, 2006). Therefore, the discrimination of the morphological elements of all C. albicans pleomorphic forms is indispensable in the mycological and histopathological diagnostics of fungal infections caused by C. albicans (Müller and Melchinger, 2006). At present, precise criteria should be completed in the medical mycological literature. Despite multiple experimental results published so far, the ultrastructure of C. albicans pleomorphic forms has not been sufficiently studied.

Previous ultrastructural analyses of C. albicans pleomorphic forms encountered difficulties (Müller and Melchinger, 2006). It is the reason of noticeable lack of precise ultrastructural characteristics of C. albicans ultrastructure, including: Spitzenkörper (Crampin et al., 2005), organization of mitosis (interphase, prophase, metaphase, anaphase, telophase), process of budding or branching, privileged areas of budding, exact features of breakable blastoconidial septum and massive true hyphal septa, occurrence of Woronon bodies, fibrillar surface of the cell wall of particular morphotypes, organization of the endoplasmic reticulum and Golgi-like structures (vesicles, cisternae), structure of biofilm and structural formation and organization of the so-called "Candida fungus ball" (Salfelder et al., 1990; Dignani et al., 2003), relations between ultrastructural characteristics and the virulence of pleomorphic forms.

The main goals of our experimental program was to search for ultrastructural characteristics of C. albicans pleomorphic forms using phase-contrast microscopy, scanning electron microscopy and transmission electron microscopy using improved 4,5\% glutaraldehyde pre-fixation method. In this paper some of the characteristics of morphotypes were discussed in terms of diagnostics, virulence of particular pleomorphic forms and sensitivity to disinfectants or antimycotics.

The findings of our study provided precise criteria of C. albicans morphotypes i.e.: precise criteria of breakable septa typical for blastoconidia and pseudohyphae, exact features of massive septa characterizing true hyphae, privileged areas of budding or branching, relations between the cultivation conditions and growth of particular pleomorphic forms, fibrous appearance at the outer surface of the cell wall of different morphotypes, cellular and hyphal organization of mycelium-like aggregates. Additionally, using our modified method of glutaraldehyde fixation some ultrastructural attributes were documented, e.g. the telophase nucleus.

The previously elaborated methods for the growth of individual morphotypes allowed us to estimate some virulence features of C. albicans pleomorphic forms, such as: profiles of enzymatic activity using the api ${ }^{\oplus}$ ZYM test (Staniszewska et al., 2010), expression of aspartic protease isoenzymes Sap1-3 and Sap4-6 using immunoelectron microscopy and immunofluorescence microscopy (immunolabelling). In comparison with blastoconidia the immunomarker of aspartic protease isoenzymes increased two times in germ tubes and four times in both pseudohyphae and true hyphae.

Biofilm-similar structures and other types of massed growth were also analyzed previously (in preparation). The so called "fungus ball" of C. albicans massed growth 
was described in diffuse parietal mycotic endocarditis. The "fungus ball" was located in the right heart ventricle and pulmonary artery of a dehydrated infant which received intravenous infusions (Salfelder et al., 1990). Our present observations allowed characterize the conglomerate arrangements composed of radiate extending true hyphae developing in undiluted human serum from aggregates of blastoconidia. The young hyphal cells located at the apex of the true hyphae which are arranged at the periphery of these spherical conglomerates seem to exhibit some enhanced virulence attributes, such as: secretion of aspartic protease isoenzymes, increased activity of tissue degradation (in preparation) and ability to develop micelial aggregates. All these results connected with profiles of enzyme activity, cellular localization and frequency of aspartic protease expression in individual morphotypes and ability to build hyphal conglomerates elucidate the relation between C. albicans pleomorphism and its virulence.

The present study shows that undiluted human serum, the temperature $37^{\circ} \mathrm{C}$ and $\mathrm{pH} \geq 7.0$ were preferable to true hyphae formation and a large fraction of the cells were induced to germinate (Fig. 2b and Fig. 3a). We modified the $\mathrm{pH}$ by transferring blastoconidia from YEPD (pH 5.7) into both undiluted ( $\mathrm{pH} 7.1-7.4$ ) and diluted ( $\mathrm{pH}$ 8.0-8.2) human sera. Findings presented in this study are consistent with observations made by other authors (Barnet, 2008; Kruppa, 2009; Noble et al., 2010). The latter showed that interconversions among the cell types are induced in vitro by modifying the $\mathrm{pH}$, temperature, and/or serum concentration in the growth medium. The morphological transition of C. albicans in response to changing environmental conditions represent a means by which the strain adapts to different biological niches (Barnet, 2008).

Presently little is known about the ultrastructural mode of fungicide action. Our previous investigations using transmission electron microscopy and scanning electron microscopy exhibited the young and very thin cell wall of buds emerging from the blastoconidial poles of C. albicans clinical isolates. At the thin cell wall of buds a collocation of mitochondrion and nucleus at the stage comparable to metaphase/anaphase was documented. Under the action of the following disinfectants: Lysoformine 3000, Medicarine, Incidin Plus, Incidin Liquid Spray and Spitaderm (antiseptic) damage of buds was presented, i.e. peeling of the outer layer of the cell wall, explosion of buds and polar holes in the cell wall. These results allowed us to suggest that during the antifungal action the blastoconidial buds are neuralgic places of the cell. This suggestion might also explain the reduction levels of viable blastoconidia exposed to the lowest concentrations of disinfectants and antiseptic (according to EN 1275:2005) which were expressed by the data from 6.2 to $7.0 \mathrm{log}$, and the survivability of the remaining blastoconidia at not budding life cycle. The authors suggested also that the speculation on different resistance and strain difference to the tested fungicides should be rooted in the composition of the especially thick and compact cell wall of C. albicans blastoconidia (Kurzątkowski et al., 2010). The resistance of particular pleomorphic forms to antibiotics is diverse and is a subject of our further investigations.

The conclusions of our work can be summarized as follows: the modified glutaraldehyde pre-fixation method allowed us more exact presentation of the fine structure of C.albicans morphotypes, the presented attributes of morphology of the particular morphotypes will facilitate the mycological and histopathological diagnostics of candidiasis, the discussed results elucidated the virulence of individual morphotypes as well as the ultrastructural mode of fungicides action.

\section{Acknowledgements}

This work was supported by Ministry of Sciences and Higher Education, Scientific Grant NN404 113639. We are very grateful to Prof. D.D. Dzierżanowska-Madalińska for kindly supplying the C. albicans strain 82 .

\section{Literature}

Barnet J.A. 2008. A history of research on yeasts 12: medical yeasts part I, Candida albicans. Yeast. 25: 385-417.

Crampin H., K. Finley, M. Gerami-Nejad, H. Court, C. Gale, J. Berman and P. Sudbery. 2005. Candida albicans hyphae have a Spitzenkörper that is distinct from the polarisome found in yeast and pseudohyphae. J. Cell. Sci. 118: 2935-2947.

Dignani M.C., J.S. Solomkin and E.J. Anaissie. 2003. Candida, pp. 195-239. In: Anaissie E.J., M.R. McGinnis and M.A. Pfaller (eds) Clinical Mycology. Churchill Livingstone, Philadelphia, USA.

Kruppa M. 2009. Quorum sensing and Candida albicans. Mycoses. 52: $1-10$.

Kuryłowicz W., W. Kurzątkowski, W. Wożnicka, H. PołowniakPracka, A. Paszkiewicz, J. Luba and J. Piorunowski. 1980. Atlas of the Ultrastructure of Penicillium Chrysogenum in the Course of Biosynthesis of Penicillin. Chemia. Warsaw.

Kurzątkowski W., M. Staniszewska and S. Tyski. 2010. Damage of Candida albicans blastoconidia exposed to biocides. Mycoses. doi:10.1111/j.1439-0507.2010.01900.x

Merson-Davies L.A. and F. Odds. 1989. A morphology index of characterization of cell shape in Candida albicans. J. Gen. Microbiol. 135: 3143-3152.

Müller J. and W. Melchinger. 2006. Ultrastructural characters defining the terms 'yeast cell', 'pseudonycelium' and 'true mycelium in Candida albicans. Mycoses. 49: 24-30.

Ness F., V. Prouzet-Mauleon, A. Vieillemard, F. Lefebvre, T. Noël, M. Crouzet, F. Doignon and D. Thoraval. 2010. The Candida albicans Rgd1 is a RhoGAP protein involved in the control of filamentous growth. Fungal Genetics and Biology 47: 1001-1011.

Netea M.G., G.D. Brown, B.J. Kullberg and N.A.R. Gow. 2008. An integrated model of the recognition of Candida albicans by the innate immune system. Nat. Rev. Microbiol. 6: 67-78.

Nguyen K.A., G. Zmeter, O. Claris and B. Kassai. 2011. Epidemiology of invasive Candida infection in a neonatal intensive care unit 
in France. Acta Paediatrica. DOI:10.1111/j. 1651-2227.2011.02514.x Noble S.M., S. French, L.A. Kohn, V. Chen and A.D. Johnson. 2010. Systematic Screens of Candida albicans homozygous deletion library decouple morphogenetic switching and pathogenicity. Nat. Genet. 42: 590-598.

Okawa Y., M. Miyauchi, S. Takahashi and H. Kobayashi. 2007. Comparison of pathogenicity of various Candida albicans and C. Stellatoidea strains. Biol. Pharm. Bull. 10: 1870-1873.

Przyjałkowski W. 2006. Fungal infections of the central nervous system (in Polish). In: Dzierżanowska D. (ed). pp. 154-165. Zakażenia grzybicze - wybrane zagadnienia. $\alpha$-medica Press, Bielsko-Biała. Raška M., J. Běláková, M. Křupka and E. Weigl. 2007. Candidiasis - do we need to fight or to tolerate the Candida fungus? Folia Microbiol. 52: 297-312.

Salfelder K., T.R. de Liscano and E. Sauertaig. 1990. Atlas of Fungal Pathology. Kluwer Academic Publishing, Dordrecht, Boston, London.

Staniszewska M., B. Rozbicka, A. Rajnisz, E. Bocian, E. Wasińska, B. Jakimiak, E. Röhm-Rodowald, W. Kurzątkowski and S. Tyski.
2010. Susceptibility of Candida spp. Clinical isolates to antimycotics and disinfectans. Cent. Eur. J. Biol. 5: 821-826.

Staniszewska M., M. Bondaryk and W. Kurzątkowski. 2011a. Morphotypes of Candida albicans. Phase-contrast microscopy. Mikologia lekarska. 18: 5-10.

Staniszewska M., D. Rabczenko and W. Kurzątkowski. 2011b. Discrimination between the enzymatic activities of Candida albicans pleomorphic forms determined using the api ${ }^{\circledR} \mathrm{ZYM}$ test. Mycoses. doi.10.1111/j.1439-0507.2010.02011.x

Stradomska T.J. 2006. Metabolites detection in the diagnosis of systemic fungal infections (in Polish). pp. 71-78. In: D. Dzierżanowska (ed). Zakażenia grzybicze - wybrane zagadnienia. a-medica Press, Bielsko-Biała.

Warzocha K. and I. Seferyńska. 2006. Fungal infections in haematology (in Polish). pp. 137-153. In: D. Dzierżanowska (ed). Zakażenia grzybicze - wybrane zagadnienia. a-medica Press, Bielsko-Biała.

Woods G.L. and V. Schnadig. 2003. Histopathology of fungal infections. pp. 80-95. In: E.J. Anaissie, M.R. McGinnis and M.A. Pfaller (eds). Clinical Microbiology. Churchill Livingstone, Philadelphia. 